\title{
Genital tuberculosis mimic as a genital malignancy in post menopausal women
}

\author{
Monalisa Mahajan* \\ Department of Gynaecology and Obstetrics, Bankura Sammilani Medical College and Hospital, Bankura, West
} Bengal, India

Received: 21 November 2020

Revised: 05 February 2021

Accepted: 06 February 2021

*Correspondence:

Dr. Monalisa Mahajan,

E-mail: monalisamahajan96@gmail.com

Copyright: $\odot$ the author(s), publisher and licensee Medip Academy. This is an open-access article distributed under the terms of the Creative Commons Attribution Non-Commercial License, which permits unrestricted non-commercial

\begin{abstract}
Genital tuberculosis tends to be an indolent infection and the disease may not manifest for year after initial seeding. The most common presentation reported in general population are pelvic pain, postmenopausal bleeding, ascites, abdominal mass, ovarian mass. The diagnosis is made by histopathological examination. Surgery is indicated as presence of abdominal pelvic mass with severe pain. Preoperative diagnosis of genital tuberculosis is often difficult because of confusion with ovarian malignancy. A 60 years old women present with weight loss, palpable abdominal mass with ascites, prominent bilateral ovaries and increase level of CA125. Pelvic malignancy was initially suspected but a diagnosis of tuberculosis was made following postoperative peritoneal wash biopsy. Patient managed with surgical laparotomy under a provisional diagnosis of ovarian malignancy but the final diagnosis was genital tuberculosis followed by anti tubercular regimen. Genital tuberculosis with high level of CA125 mimicking ovarian carcinoma.
\end{abstract}

Keywords: Genital tuberculosis, Langhans type giant cells, CA125

\section{INTRODUCTION}

Genital tuberculosis in females is by no means uncommon; particularly in communities where pulmonary tuberculosis or other forms of extra genital tuberculosis are common. ${ }^{1}$ Genital tuberculosis frequently present without symptom and diagnosis require a high index of suspicion. The disease can mimic many conditions including bowel disease, malignancy, and other infectious disease. The serum cancer antigen CA125 can be elevated in both ovarian cancer and genital tuberculosis. $^{2}$ Tuberculosis is considered the most important communicable disease in world. ${ }^{3}$ Genital tuberculosis after menopause is rare, probably because of the decrease vascularity of the tissue. After menopause it usually present with symptoms resembling ovarian sol as abdominal distension, severe pain in abdomen, weight loss.

\section{CASE REPORT}

A 60 years old woman was suffering from abdominal distension with abdominal pain for last 6 months. She has poor appetite, general malaise, weight loss but denied any tarry stool or diarrhea. Menopause occurs 10 years ago. No bleeding per vagina after menopause. No family history, no other systemic disease. Patient also denied any cough, shortness of breath, wheeze and any past of tuberculosis.

\section{Investigations}

Haemoglobin; $9.4 \mathrm{gm} / \mathrm{dl}$, serum urea; $22 \mathrm{mg} \%$, serum creatinine; $0.70 \mathrm{mg} \%$, serum sodium, $136.4 \mathrm{mmol} / \mathrm{l}$, serum potassium; $3.79 \mathrm{mmol} / \mathrm{l}$, prothrombin time; 14.2 seconds, fasting blood sugar; $87 \mathrm{mg} / \mathrm{dl}$, INR; 1.06, activated partial thromboplastin time; 34 seconds, 
echocardiography; normal study, chest X-ray; within normal limit, serology; negative, CA 125-55.

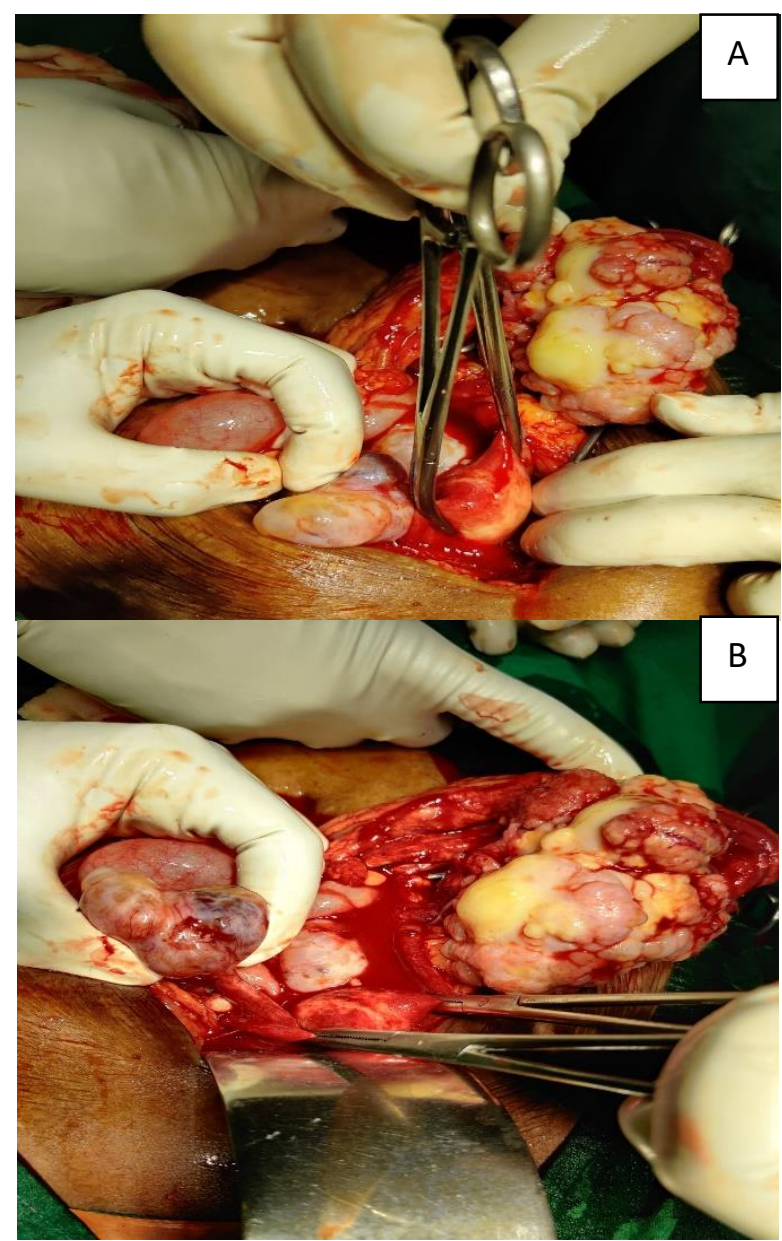

Figure 1: Ovarian mass.

\section{CT scan of whole abdomen}

Enhancing multiloculated cystic lesions were observed in both adnexa adhered to uterus likely neoplastic ovarian sol. Large ascites were observed. Enhancing sol in greater omentum likely deposit and dilated small bowel loops were also observed.

\section{Management}

Management was done by doing laparotomy under general anaesthesia. On opening of abdomen by longitudinal incision mass found to be adherent to peritoneum and uterus. Peritoneal washing collected specimen taken from cyst wall and mass from peritoneum (suspected ovarian mass). Then specimen was send for histopathological examination.

\section{Peritoneal wash for M cell, protein, sugar}

No malignant cells were observed. Protein was observed to be 1.37 and sugar was observed to be; $46.3 \mathrm{mg} / \mathrm{dl}$.

\section{Histopathological examination}

Histopathological section showed fibrocollagenous evidence of extensive haemorrhage and necrosis with focal presence of caseating granuloma containing foreign body type as well as langhans type giant cells. No ovarian follicle was identified in sections. Overall features were consistent with the diagnosis of chronic granulomatous lesion with caseation, possibility of kochs' etiology was considered. So, patient was then advised for anti tubercular regimen category 1 under DOTS.

\section{DISCUSSION}

Genital tuberculosis is an uncommon extra-pulmonary manifestation of tuberculosis with a potential to cause for significant mortality and morbidity. ${ }^{4}$ Female genital tuberculosis prevalence is generally underestimated because of the asymptomaic nature of the infection and diagnostic challenges. CA-125, the common tumor marker of ovarian cancer, is also elevated in patients with pulmonary and extrapulmonary tuberculosis. ${ }^{5}$ This is because CA-125 antigen is a large transmembrane glycoprotein derived from coelomic and mullerian epithelium. Elevation of CA 125 antigen can be caused by ovarian cancer and other malignancies. ${ }^{6}$ So current case report of genital tuberculosis with pelvic abdominal masses, ascites and elevated-125 mimicked advanced ovarian carcinoma. ${ }^{7}$ Genital tuberculosis causes chronic pelvic pain, ascites, abdominal lump. Diagnosis was made by meticulous history thorough clinical examination and proper use of investigations, particularly peritoneum wash for histopathological examination. Treatment was done through the DOTS category 1 antitubercular regimen.

\section{CONCLUSION}

Female genital tuberculosis must be taken into account in the patients with different clinical symptoms. Since mimicking genital tuberculosis with genital carcinoma is a histopathological diagnosis, it is important to keep its diagnosis in mind while reporting genital malignancy. While evaluating any patient in outpatient department or emergency room, one should always keep in mind the possibility of tuberculosis, especially in endemic areas. It is better to go for surgical intervention to directly visualize the disease and obtain material for histopathological examination which should clinch the diagnosis in majority of cases.

\section{Funding: No funding sources \\ Conflict of interest: None declared \\ Ethical approval: Not required}

\section{REFERENCES}

1. Global tuberculosis report 2012, the burden of disease cause by TB. Available at: https://www.who. 
int/tb/publications/global_report/gtbr12_main.pdf. Accessed on 20 September 2020.

2. Sachan R, Patel ML, Gupta P, Verma AK. Genital tuberculosis with variable presentation: a series of three cases. BMJ Case Rep. 2012;2012: bcr2012006665.

3. Rock J, Jones HW. TeLindes operative gynecology. 10th ed. Philadelphia: Lippincott Williams and Wilkins; 2008:30;677-8.

4. Marques-Mendes E, Meireles-Brandão L, Meira C, Morais N, Ribeiro C, Guerra D. Primary hypoparathyroidism presenting as basal ganglia calcification secondary to extreme hypocalcemia. Clin Pract. 2018;8(1):1007.

5. Adali E, Dulger C, Kolusari A, Kurdoglu M, Yildizhan R. Pelvic-peritoneal tuberculosis simulating peritoneal carcinomatosis: High clinical suspicion and a minimally invasive procedure. Arch Gynecol Obstet. 2009;280:867-8.

6. Kumar S. Tuberculosis. 2nd ed. India: Jaypee Brothers Medical Publishers; 2009:452-3.

7. Tinelli A, Malvasi A, Vergara D. Abdominopelvic tuberculosis in gynaecology: laparoscopical and new laboratory findings. Aust N Z J Obstet Gynaecol. 2008;90-5.

Cite this article as: Mahajan M. Genital tuberculosis mimic as a genital malignancy in post menopausal women. Int J Reprod Contracept Obstet Gynecol 2021;10:1195-7. 